\title{
Antibacterial Activity of Essential Oils Extracted From the Unique Chinese Spices Cassia Bark, Bay Fruits, and Cloves
}

Chunling Jiang

Shanghai Ocean University https://orcid.org/0000-0003-2053-8046

Jing Meng

Tongji University Shanghai First Maternal and Infant Hospital

Jie Ou

Shanghai Ocean University

Qingchao Xie

Shanghai Ocean University

Yingjie Pan

Shanghai Ocean University

Yong Zhao

Shanghai Ocean University

Haiquan Liu ( $\sim$ hqliu@shou.edu.cn )

Shanghai Ocean University

\section{Research Article}

Keywords: Essential oil(EO), Antibacterial, Cinnamomum, Laurus, Cloves, Unique

Posted Date: February 21 st, 2022

DOl: https://doi.org/10.21203/rs.3.rs-1245027/v1

License: (1) This work is licensed under a Creative Commons Attribution 4.0 International License. Read Full License 


\section{Abstract}

Spices are widely used in daily life such as diet and have certain activity. Especially in China, spices have been mainly used as condiments for thousands of years in order to improve the sensory quality of food; in addition, they and their derivatives can also be used as preservatives. In this study, three species with Chinese characteristics unique and widely used by the public were selected: cassia bark (bark of Cinnamomum camphoraPresl), bay fruits (Laurus nobilis), and cloves (Syzygiumaromaticum). The main components and antibacterial ability of these three spices were analyzed by simulated extraction method. Through headspace solid-phase microextraction (HS-SPME) and gas chromatography-mass spectrometry (GC-MS) analysis, it was determined that the main active compounds in the essential oils of cassia bark, bay fruits and cloves were cinnamaldehyde (78.11\%), cinnamaldehyde (61.78\%), and eugenol (75.23\%), respectively. The agar plate diffusion test and the simulated food culture medium experiment confirmed that the essential oils extracted from the three flavors have antibacterial effects on Vibrio

parahaemolyticus, Listeria monocytogenes and 4 kinds of Listeria. The antibacterial activity of different strains has different optimal extraction conditions. Generally speaking, cinnamon essential oil has the strongest antibacterial activity, while laurel fruit has the lowest antibacterial activity. The study proved the antibacterial activity of these three Chinese-specific spices, and provided some new ideas and methods for the subsequent research and preparation of natural food additives and food antibacterial agents.

\section{Introduction}

Many minimally processed foods are added with preservatives to extend their shelf lives, but consumers have questioned the safety of chemical additives and demanded for the removal of chemical additives from foods(Masri et al., 2021). This has resulted in an increasing interest in searching for preservatives from natural sources that can be used in foods to improve quality and safety(Calvo et al., 2021; da Silva et al., 2021; Pandey et al., 2021).

Vibrio parahaemolyticus is a Gram-negative bacterium which causes acute gastroenteritis in humans consuming contaminated seafoods(Yang et al., 2019). Since a great number of food-poisoning incidents were caused by $V$. parahaemolyticus, efforts are needed to enhance the safety of seafood(Rui et al., 2019; Zhiwei et al., 2019). Listeria monocytogenes is widely present in the environment owing to its versatile physiological adaptation mechanisms. Due to it high tolerance to adverse environmental conditions, L. monocytogenes is frequently found in foodprocessing environments and minimally processed foods(Pasonen et al., 2019; A et al., 2019; Wu et al., 2020). Moreover, its ability to grow at refrigeration temperatures increases the risk of foodborne illnesses caused by refrigerated foods contaminated with L.monocytogenes. Therefore, it is important to control the growth $L$. monocytogenes in refrigerated minimally processed foods.

The development of bacterial resistance to antibiotics is a serious problem. Reports of antibiotic-resistant bacteria causing increased morbidity and mortality have been published in the past two decades(Noman et al., 2021; Lv et al., 2021). There is a great concern of the overuse of antibiotics and the dissemination of multi-resistant bacteria through the food chain, trade and human migration(Ding et al., 2021; Mahros et al., 2021). Spices and herbs can be considered essential and natural components of the human diet; they not only impart food taste and flavor but also have considerable beneficial physiological effects on human health, such as antimicrobial(Mendes et al., 2017; Otunola and Afolayan, 2018; Qing et al., 2017), anti-inflammatory(Serafini and Peluso, 2016; Zhang et al., 2016; Ashktorab et al., 2019; Chin, 2016), and antioxidant effects(Mendes et al., 2017; Sepahpour et al., 2018; Yashin et al., 2017). The use of spices or their derivatives as antimicrobials in food products provide an alternative to the use of chemical preservatives in foods for shelf life and safety purposes(Tshabalala et al., 2021; El-Sayed and Youssef, 2019). 
Cassia, which is called Chinese cinnamon (Cinnamomum cassia Presl), is a small evergreen tree native to southern China. The bark and twigs of Cinnamomum plant have long been used as a source of aromatic spices worldwide (HelmyAbdou et al., 2019; Zhang et al., 2019). Laurus nobilis is an evergreen tree that can grow up to $8 \mathrm{~m}$ in height and widely cultivated in southern China. Bay leaf extracts have been investigated for their wound healing, cytotoxic, and trypanocidal properties (Fidan et al., 2019), and bay fruits are commonly used as a folk medicine in China. Cloves are the aromatic dried flower buds of Syzygiumaromaticum in the family Rhodomyrtus tomentosa. It is one of the most used and known spices in the world. Although its use in the Western countries is mainly limited to the flavoring and preservation of foods, cloves have been long used for its drug-like properties in Asian countries(Kheawfu et al., 2018; Juan et al., 2019; Tshabalala et al., 2021). The aim of this work was to determine the antimicrobial activity of essential oils extracted from the three spices, which are widely cultivated in China, and identify the active antimicrobial compounds in the essential oils.

\section{Materials And Methods}

\section{Plant materials and chemicals culture media.}

Cassia bark, bay fruits, and cloves, which were harvested in Guiping Country of Guangxi Province, Chuxiong Country of Yunnan Province and Qingyun Country of Shandong Province, respectively. The three spices were obtained as a commercial product in the market of Shanghai. Samples were kept in dark at $25^{\circ} \mathrm{C}$. Brain heart infusion broth (BHIB) was purchased from Oxoid (Basingstoke,UK). Tryptone soy broth (TSB), tryptic soy agar (TSA), and nutrient agar (NA) were obtained from Beijing Land Bridge Technology Company (Beijing, China).

\section{Microorganisms.}

The antimicrobial activities of the essential oils were tested against six different bacteria; L. monocytogenes ATCC19117 (LM), L. innocua ATCC33090 (LI), L. welshimeri ATCC43548 (LW), L. ivanovii ATCCBAA-678 (LL), L. grayi ATCC25400 (LG) and V. parahaemolyticus ATCC33847 (VP). These strains were maintained in glycerol broth at $-80^{\circ} \mathrm{C}$. Frozen cultures of Listeria spp. and $V$. parahaemolyticus were revised in $8 \mathrm{ml}$ of $\mathrm{BHIB}$ and TSB added with $2 \%$ $\mathrm{NaCl}(2 \% \mathrm{NaCl} \mathrm{TSB})$, respectively, and incubated overnight at $37^{\circ} \mathrm{C}$ in a rotary shaker (180 rpm) (Huang et al., 2020). Subculture the culture again by inoculating $0.1 \mathrm{ml}$ of overnight culture in $\mathrm{BHI}$ or $2 \% \mathrm{NaCl} \mathrm{TSB}$, and incubate overnight at $37^{\circ} \mathrm{C}$ in a rotary shaker $(180 \mathrm{rpm})$ to a final population of approximately $108 \mathrm{CFU} / \mathrm{ml}$.

\section{Extraction of Essential Oil and Optimal Extraction Parameters.}

Four hundred grams of the three spices were washed with tap water twice, air-dried in a ventilated oven at $50^{\circ} \mathrm{C}$ for $24 \mathrm{~h}$, and then ground into fine powder using a commercial blender (Waring Laboratory, Torrington, CT, USA). Spice powder was screening by passing through a sieve $\left(60\right.$-mesh) and stored in polythene bags at $4^{\circ} \mathrm{C}(\mathrm{Bajalan}$ et al., 2017).

The extracts of the spices were obtained with the aid of ethanol solutions and an ultrasound machine. The extraction parameters were examined to find an optimal extract conditions that yielded extracts that had the highest antimicrobial activity against $L$. monocytogenes and $V$. parahaemolyticus, respectively. The extract parameters included the ratio of spice to ethanol, ethanol concentration, extraction temperature, extraction time, and the power level and time of the ultrasound extraction. Table 1 summarizes the ranges of variables investigated. Five grams of each powdered spice were added to $125 \mathrm{ml}$ of $50 \%$ ethanol in a $250 \mathrm{ml}$ Erlenmeyer flask. The flask was sealed with a polypropylene cap and the extraction was performed on at $40^{\circ} \mathrm{C}$ for $3 \mathrm{~h}$ in a rotary shaker $(180 \mathrm{rpm})$. Ultrasoundassisted extraction was conducted in an ultrasonic processor (Ningbo Scientz Biotechnology Co., Ningbo, China) with 
the selected powder and sonicated for $25 \mathrm{~min}$. The extractives were centrifuged at $3500 \times \mathrm{g}$ for $10 \mathrm{~min}$ and the supernatant was recovered after filtering through a $0.45 \mu \mathrm{m}$ filter paper (Whatman No. 1). The supernatant solvent in the supernatants was evaporated in a rotary evaporator (Shanghai SENCO Technology Co., Shanghai, China) under vacuum $(30 \mathrm{mmHg})$ at room temperature to recover essential oils. The essential oil was dissolved in sterile Milli-Q water to achieve the essential oil concentration at $100 \mathrm{mg} / \mathrm{ml}$. The essential oils were stored in airtight, sterile vials at $4^{\circ} \mathrm{C}$. The antimicrobial activity of essential oils obtained from different extraction parameters were evaluated using agar-disc diffusion assay (with some modifications. Listeria spp. and V. parahaemolyticus (0.1 ml at $108 \mathrm{CFU} / \mathrm{ml})$ was spread with a sterile swab on TSA (for Listeria spp.) or $2 \% \mathrm{NaCl}$ TSA (for $V$. parahaemolyticus) plates and allowed to absorb for 15 minutes. Three disks of Whatman No. 1 sterile filter paper, $6 \mathrm{~mm}$ in diameter, impregnated with each essential oil $(100 \mathrm{mg} / \mathrm{ml})$ were placed on the inoculated agar surfaces. Disks with Milli-Q water were used as control. The plates were incubated at $37^{\circ} \mathrm{C}$ for $24 \mathrm{~h}$ and examined for zones of inhibition. A positive antibacterial activity was recorded when an inhibition zone was greater than $6 \mathrm{~mm}$ (Chen et al., 2019).

Table 1

The ranges of variables investigated.

\begin{tabular}{|ll|}
\hline Parameters & Ranges \\
\hline Spice to ethanol ratio & $1: 5,1: 10,1: 15,1: 20,1: 25$ \\
\hline Ethanol concentration $(\%, \mathrm{v} / \mathrm{v})$ & $10 \%, 30 \%, 50 \%, 70 \%, 95 \%$ \\
\hline Extraction temperature & $40^{\circ} \mathrm{C}, 50^{\circ} \mathrm{C}, 60^{\circ} \mathrm{C}, 70^{\circ} \mathrm{C}, 80^{\circ} \mathrm{C}$ \\
\hline Extraction time (h) & $0,2,4,6,8$ \\
\hline Ultrasonic power (W) & $200,250,300,350,400$ \\
\hline Ultrasonic time (min) & $15,30,45,60,75$ \\
\hline
\end{tabular}

\section{Antimicrobial Activity of Essential Oils}

To confirm the antimicrobial activity of the essential oils in a medium that simulated food products, the essential oils were tested against the six bacterial strains in TSB. Each essential oil at $0.5 \mathrm{ml}(100 \mathrm{mg} / \mathrm{ml})$ was added into each test culture of $9.5 \mathrm{ml}\left(10^{8} \mathrm{CFU} / \mathrm{ml}\right)(1: 10$, corresponding to $10 \mathrm{mg}$ essential oil/ml). The control consisted of $0.5 \mathrm{ml}$ Milli-Q water and $9.5 \mathrm{ml}$ cultures. The cultures were incubated at $37^{\circ} \mathrm{C}$ for $16 \mathrm{~h}$ in a rotary shaker (180 rpm). After incubation, $1 \mathrm{ml}$ of culture was serially diluted in $9 \mathrm{ml}$ sterile $0.1 \%$ peptone water, and $0.1 \mathrm{ml}$ of appropriate dilutions was spread in duplicate onto TSA, 2\%TSA, PALCAM and TCBS to enumerate viable Listeria spp., viable $V$. parahaemolyticus, uninjured Listeria spp. and $V$. parahaemolyticus, respectively. The experiment was performed three times.

\section{Isolation and analysis of the volatile compounds of the spice essential oil by headspace solid-phase microextraction (HS-SPME) and gas chromatography-mass spectrometry (GC-MS).}

After several preliminary tests to optimize the extraction system, $4 \mathrm{ml}$ of essential oil and $100 \mu \mathrm{l}$ of $250 \mathrm{~g} / \mathrm{L} \mathrm{NaCl}$ (to favor the transfer of the analytes from the aqueous solution to the headspace) were placed in a $15 \mathrm{ml}$ glass vial with a polypropylene screw-on cap and a polytetrafluoroethylene/silicone septum (Supelco, Bellefonte, PA, USA) to create an airtight seal. The volume ratio of the essential oil to headspace was approximately 1:3. The glass jar was placed in a water bath with temperature control and agitated with a stir bar. The headspace in glass vials were equilibrated with the volatile compounds at $55^{\circ} \mathrm{C}$ for $5 \mathrm{~min}$ in the bath. Headspace volatiles of crude extraction were isolated 
using a 50/30 $\mu \mathrm{m}$ Divinylbenzene/CARBOXEN/Polydimethylsiloxane fiber (Supelco) inserted through the septum and exposed in the headspace for $30 \mathrm{~min}$ at $55^{\circ} \mathrm{C}$ to allow absorption of the volatile compounds. The fibers were selected for its high capacity of trapping volatile compounds and were conditioned for $30 \mathrm{~min}$ at $250^{\circ} \mathrm{C}$ before use. After sampling, desorption of the volatile compounds from the fiber coating was carried out in the injection port of a gas chromatography-mass spectrometry (GC-MS) during $5 \mathrm{~min}$ in split mode set at $250^{\circ} \mathrm{C}$ (Bajpai et al., 2013).

The identification of volatile compounds was performed using an Agilent 6890N Network GC system combined with an Agilent 5975 B Inert MSD detector (quadruple) in the electron impact mode (70 eV). The GC-MS system was equipped with a SLB-5ms capillary column (Supelco), 95\% dimethyl siloxane and $5 \%$ diphenyl $(60 \mathrm{~m} \times 250 \mu \mathrm{m}$ i.d. $\times 0.25 \mu \mathrm{m}$ film thickness). Helium was used as carrier gas at a flow rate of $1.0 \mathrm{ml} / \mathrm{min}$ with a pressure of $15.60 \mathrm{psi}$ and the following program: (a) $65^{\circ} \mathrm{C}$ for $5 \mathrm{~min}$; (b) rate of $4.0 \mathrm{ml} / \mathrm{min}$ from 40 to $100^{\circ} \mathrm{C}$ and hold for $5 \mathrm{~min}$; (c) rate of $2 \mathrm{ml} / \mathrm{min}$ from 100 to $150^{\circ} \mathrm{C}$ and hold for $2 \mathrm{~min}$; (d) rate of $5 \mathrm{~mL} / \mathrm{min}$ from 150 to $190^{\circ} \mathrm{C}$ and hold for $2 \mathrm{~min}$; (e) rate of $15 \mathrm{~mL} / \mathrm{min}$ from 190 to $250^{\circ} \mathrm{C}$ and hold for $2 \mathrm{~min}$. Detector was held at $270^{\circ} \mathrm{C}$.

The compounds were identified by comparing their Kovats indices (KI), GC retention times (authentic chemicals), NIST mass spectral search program (version 2.0, National Institute of Standards and Technology) and mass spectra of published data. For each compound, quantification was performed by measuring the corresponding peak area of the total ion chromatogram and expressed as relative (percent) areas by normalization.

\section{Statistical analysis.}

All experiments were repeated three times. Analysis of variance (ANOVA) was performed on zone of inhibition and cell counts using SPSS 15.0 (SPSS Inc., Chicago, III., U.S.A.). The level of significance of was set at $a=0.05$.

\section{Results And Disscussion}

\section{Optimal Extraction Parameters.}

The antimicrobial efficacy of the essential oils obtained from different extract conditions against $V$. parahaemolyticus and Listeria spp. are shown in Table 2. All of the essential oils showed antimicrobial activity. Generally, essential oil of cassia bark showed highest antimicrobial activity $(p<0.05)$ followed by bay fruits and cloves. $V$. parahaemolyticus was more sensitive than Listeria spp. to the three essential oils. In particular, the inhibition diameters of cassia bark spice essential oils ranged from 9.1 to $21.0 \mathrm{~mm}$ for $V$. parahaemolyticus. There were only 12 crude extracts, which were significantly different $(P<0.05)$ from the other essential oils as well as the control. The optimum extraction conditions for obtaining essential oils with the highest antimicrobial potentials are listed in Table 2. For the experimental parameters, we chose the value of an experimental variable that gave the maximal mean zones of inhibition against the tested strains, significantly different from other values. Furthermore, we considered the efficiency of different values of experimental parameters. Table 3 shows the optimal extraction conditions of the three spices against the tested strains. 
Table 3

The optimum extraction conditions of the three spices to every tested strains

\begin{tabular}{|c|c|c|c|c|c|c|c|c|}
\hline \multirow[t]{2}{*}{ ID } & \multirow[t]{2}{*}{ Spice } & \multicolumn{6}{|c|}{ Extraction conditions } & \multirow{2}{*}{$\begin{array}{l}\text { Tested } \\
\text { Strain }\end{array}$} \\
\hline & & $\begin{array}{l}\text { Spice to } \\
\text { Ethanolratio }\end{array}$ & $\begin{array}{l}\text { Ethanol } \\
\text { concentration }\end{array}$ & $\begin{array}{l}\text { Extraction } \\
\text { temperature }\end{array}$ & $\begin{array}{l}\text { Extraction } \\
\text { time }\end{array}$ & $\begin{array}{l}\text { Ultrasonic } \\
\text { power }\end{array}$ & $\begin{array}{l}\text { Ultrasonic } \\
\text { time }\end{array}$ & \\
\hline LM1 & \multirow{6}{*}{$\begin{array}{l}\text { cassia } \\
\text { bark }\end{array}$} & $100 \mathrm{ml}$ & $50 \%$ & $40^{\circ} \mathrm{C}$ & $2 \mathrm{~h}$ & $250 \mathrm{~W}$ & $15 \min$ & LM \\
\hline LI1 & & $100 \mathrm{ml}$ & $50 \%$ & $40^{\circ} \mathrm{C}$ & $2 \mathrm{~h}$ & $200 W$ & $30 \mathrm{~min}$ & $\mathrm{LI}$ \\
\hline LW1 & & $100 \mathrm{ml}$ & $50 \%$ & $40^{\circ} \mathrm{C}$ & $2 \mathrm{~h}$ & $200 \mathrm{~W}$ & $15 \mathrm{~min}$ & LW \\
\hline LL1 & & $100 \mathrm{ml}$ & $50 \%$ & $40^{\circ} \mathrm{C}$ & $2 \mathrm{~h}$ & $250 \mathrm{~W}$ & $30 \mathrm{~min}$ & LL \\
\hline LG1 & & $100 \mathrm{ml}$ & $50 \%$ & $40^{\circ} \mathrm{C}$ & $2 \mathrm{~h}$ & $250 \mathrm{~W}$ & $15 \mathrm{~min}$ & LG \\
\hline VP1 & & $50 \mathrm{ml}$ & $95 \%$ & $60^{\circ} \mathrm{C}$ & $2 \mathrm{~h}$ & $250 \mathrm{~W}$ & $15 \mathrm{~min}$ & VP \\
\hline LM2 & \multirow{6}{*}{$\begin{array}{l}\text { bay } \\
\text { fruits }\end{array}$} & $75 \mathrm{ml}$ & $50 \%$ & $40^{\circ} \mathrm{C}$ & $2 \mathrm{~h}$ & $250 \mathrm{~W}$ & $15 \min$ & LM \\
\hline LI2 & & $100 \mathrm{ml}$ & $50 \%$ & $70^{\circ} \mathrm{C}$ & $2 \mathrm{~h}$ & $200 W$ & $30 \mathrm{~min}$ & $\mathrm{LI}$ \\
\hline LW2 & & $75 \mathrm{ml}$ & $50 \%$ & $40^{\circ} \mathrm{C}$ & $2 \mathrm{~h}$ & $250 \mathrm{~W}$ & $30 \mathrm{~min}$ & LW \\
\hline LL2 & & $100 \mathrm{ml}$ & $50 \%$ & $40^{\circ} \mathrm{C}$ & $4 \mathrm{~h}$ & $250 \mathrm{~W}$ & $15 \mathrm{~min}$ & LL \\
\hline LG2 & & $100 \mathrm{ml}$ & $50 \%$ & $40^{\circ} \mathrm{C}$ & $2 \mathrm{~h}$ & $300 \mathrm{~W}$ & $75 \mathrm{~min}$ & LG \\
\hline VP2 & & $50 \mathrm{ml}$ & $70 \%$ & $40^{\circ} \mathrm{C}$ & $2 \mathrm{~h}$ & $250 \mathrm{~W}$ & $15 \mathrm{~min}$ & VP \\
\hline LM3 & \multirow[t]{6}{*}{ cloves } & $50 \mathrm{ml}$ & $50 \%$ & $40^{\circ} \mathrm{C}$ & $2 \mathrm{~h}$ & $200 \mathrm{~W}$ & $15 \min$ & LM \\
\hline LI3 & & $75 \mathrm{ml}$ & $50 \%$ & $40^{\circ} \mathrm{C}$ & $2 \mathrm{~h}$ & $200 \mathrm{~W}$ & $15 \mathrm{~min}$ & $\mathrm{LI}$ \\
\hline LW3 & & $75 \mathrm{ml}$ & $50 \%$ & $40^{\circ} \mathrm{C}$ & $2 \mathrm{~h}$ & $200 \mathrm{~W}$ & $60 \mathrm{~min}$ & LW \\
\hline LL3 & & $100 \mathrm{ml}$ & $70 \%$ & $40^{\circ} \mathrm{C}$ & $2 \mathrm{~h}$ & $200 \mathrm{~W}$ & $15 \min$ & LL \\
\hline LG3 & & $125 \mathrm{ml}$ & $50 \%$ & $40^{\circ} \mathrm{C}$ & $2 \mathrm{~h}$ & $200 \mathrm{~W}$ & $30 \mathrm{~min}$ & LG \\
\hline VP3 & & $125 \mathrm{ml}$ & $50 \%$ & $40{ }^{\circ} \mathrm{C}$ & $2 \mathrm{~h}$ & $200 \mathrm{~W}$ & $15 \min$ & VP \\
\hline
\end{tabular}

\section{Antimicrobial Activity of Essential Oils.}

The antimicrobial activity of the three essentials oils obtained with the optimum extraction parameters against the six bacterial are listed in Fig. 1.Generally, the antimicrobial activity of essential oil of cassia bark was more significant than the essential oils of bay fruits and cloves. The inhibitory values were different; that were evaluated with non-selective agar (TSA) and selective agar (TCBS and PALCAM). The different results of non-selective agar and selective agar showed there were some injured bacteria that might be repaired on non-selective agar. The essential oil of cassia bark with VP1 extraction condition had the highest antimicrobial activity against V. parahaemolyticus and can reduce $8.3 \mathrm{log}$ CFU/ml evaluated with TCBS agar. The essential oil of bay fruits with VP2 extraction condition had the lowest antimicrobial activity against $L$. innocua and only reduced the bacterial count by $0.13 \mathrm{log} C F U / \mathrm{ml}$ when evaluated with TSA agar. 
Most of the antimicrobial activity of the essential oil using the six extraction conditions against each strain was significantly different. As seen in Table 4, the extraction condition had more of an effect on the antimicrobial activity of cassia bark and cloves extracts against bacteria. The strains L. grayi ATCC25400 and V. parahaemolyticus ATCC33847 are more sensitive to all of the extracts, even with different extraction conditions. The results of in vitro susceptibility of crude extracts of the three spices have antibacterial activity against $V$. parahaemolyticus and Listeria spp.. 
Table 4

Analysis of the common volatile compounds of ethanol extract of the spices with optimal extraction conditions against six bacterial as determined using headspace solid-phase microextraction (HS-SPME) and gas chromatography coupled to mass spectrometry (GC-MS) methods ${ }^{\text {a }}$

\section{No Name of the compound}

\section{Cassia bark}

11 Benzenepropanal

1

2 2-Propenal, 3-phenyl-

3 2-Propen-1-ol, 3-phenyl-

4 2-Propen-1-ol, 3-phenyl-, acetate

5 eugenol,

$6 \quad$ Naphthalene, 1,2,3,4-tetrahydro-1,6dimethyl-4-(1-methylethyl)-, (1S-cis)-

\section{Bay fruits}

2-Propenal, 3-phenyl-

Copaene

Caryophyllene

2H-1-Benzopyran-2-one

2-Propenoic acid, 3-phenylethyl ester

Naphthalene,

$1,2,3,4,4 a, 5,6,8 a-o c t a h y d r o-$

7-methyl-4-methylene-1

-(1-methylethyl)-,

(1à,4aà,8aà)-

7 Isolongifolene, 4,5,9,10-dehydro-

8 à-Calacorene

10 Cubenol

11 tau.-Muurolol

12 1-Naphthalenol, 1,2,3,4,4a,7,8,8aoctahydro-1,6-dimethyl-4-(1methylethyl)-, [1R-(1à,4á,4aá,8aá)]-

13 à-Cadinol

14 3-Cyclohexen-1-ol, 1-(1,5-dimethyl-4hexenyl)-4-methyl-

15 à-Bisabolol

16
Benzene, 1-(1,5-dimethyl-4hexenyl)-4-methyl-

Naphthalene, 1,2,4a,5,6,8ahexahydro-4,7-dimethyl-1-(1methylethyl)-,

(1à,4aà,8aà)-

Cyclohexene, 1-methyl-4-(5- Caryophyllene oxide methyl-1-methylene-4hexenyl)-, (S)-

Naphthalene, 1,2,4a,5,8,8ahexahydro-4,7-dimethyl-1-(1methylethyl)-,

[1S-(1à,4aá,8aà)]-

Naphthalene, 1,2,3,412-Oxabicyclo[9.1.0]dodeca-3,7diene, 1,5,5,8-tetramethyl-, [1R$\left.\left(1 R^{\star}, 3 E, 7 E, 11 R^{\star}\right)\right]-$

Phenol, 2-methoxy-4-(2propenyl)-, acetate

2,3,3a,4,5,6,7,7a-Octahydro-1 Hcyclopenta[a]pentalen-7-ol
Phenol, 2-methoxy-4-(1propenyl)-, (E)-

à-Caryophyllene

à-Farnesene tetrahydro-1,6-dimethyl-4-(1methylethyl)-, (1S-cis)-

à-Calacorene

Cyclooctasiloxane, hexadecamethyl-

Tetracyclo[6.3.2.0(2,5).0(1,8)] tridecan-9-ol, 4,4-dimethyl-

1,6,10-Dodecatrien-3-ol, 3,7,11-trimethyl-, (E)-

Murolan-3,9(11)-diene-10peroxy

Caryophyllenyl alcohol

(-)-Spathulenol
Caryophyllene oxide

Benzyl Benzoate 


\begin{tabular}{|c|c|c|}
\hline \multirow[t]{2}{*}{ No } & \multicolumn{2}{|c|}{ Name of the compound } \\
\hline & Cassia bark & Bay fruits \\
\hline 17 & & Isoaromadendrene epoxide \\
\hline 18 & & Globulol \\
\hline 19 & & $\begin{array}{l}\text { 3,7-Cycloundecadien-1-ol, } \\
\text { 1,5,5,8-tetramethyl- }\end{array}$ \\
\hline 20 & & Cubenol \\
\hline 21 & & $\begin{array}{l}\text { 4-(2,4,4-Trimethyl-cyclohexa- } \\
\text { 1,5-dienyl)-but-3-en-2-one }\end{array}$ \\
\hline 22 & & à-Cadinol \\
\hline 23 & & $\begin{array}{l}\text { 1-Naphthalenol, 1,2,3,4,4a,7,8,8a-octahydro-1,6-dimethyl-4-(1- } \\
\text { methylethyl)-, [1RR-(1â,4á,4aá,8aá)]- }\end{array}$ \\
\hline 24 & & $\begin{array}{l}\text { 2-Furanmethanol, tetrahydro-à,à,5-trimethyl-5-(4-methyl-3- } \\
\left.\left.\left.\text { cyclohexen-1-yl)-, [2S-[2à,5á( } R^{\star}\right)\right]\right]-\end{array}$ \\
\hline 25 & & 3-Cyclohexen-1-ol, 1-(1,5-dimethyl-4-hexenyl)-4-methyl- \\
\hline 26 & & Longiverbenone \\
\hline 27 & & à-Bisabolol \\
\hline 28 & & $\begin{array}{l}\text { Acetic acid, 3-hydroxy-6-isopropenyl-4,8a-dimethyl- } \\
1,2,3,5,6,7,8,8 \text { a-octahydronaphthalen-2-yl ester }\end{array}$ \\
\hline
\end{tabular}

aThe table listed the common components of each spice. The peak area, peak (\%) and RT(retention time) (min ) of the same components of each spice with different extraction conditions were different.

\section{Volatile compounds in Essential Oils.}

There were 15, 29 and 14 common compounds isolated and identified from the essential oils of cassia bark, bay fruits, and cloves, respectively (Table 4). Only 3-Phenyl-2-propenal (cinnamaldehyde) was the common compound among the three spices.

The peak area, peak (\%) and RT ( $\mathrm{min}$ ) of same compound using different extraction conditions were different for each spice (Fig. 2). The main common compounds were found in the same spice with different extraction conditions. The major components in essential oil of cassia bark (Cinnamomum camphoraPresl) were 3-phenyl-2-propenal (cinnamaldehyde), 3-phenyl-2-propen-1-ol acetate, eugenol, cubenol and tau.-muurolol. The relative amounts in LG1 extracts were $78.11 \% \pm 2.65 \%, 4.11 \% \pm 2.53 \%, 2.73 \% \pm 0.28 \%, 2.55 \% \pm 1.42 \%$ and $1.31 \% \pm 0.30 \%$, respectively. The main common compounds of bay fruits (Laurus nobilis) extracts were 3-phenyl-2-propenal (cinnamaldehyde), cubenol, à-Cadinol and 1,2,4a,5,6,8a-Hexahydro-4,7-dimethyl-1-(1-methylethyl) naphthalene. The content in LW2 extracts were $61.78 \% \pm 15.58 \%, 2.73 \% \pm 0.85 \%, 2.65 \% \pm 0.38 \%$ and $2.24 \% \pm 1.65 \%$, respectively. The main common compounds of cloves extracts were eugenol, eugenol acetate[Phenol, 2-methoxy-4-(2-propenyl)-acetate] and caryophyllene. The content in LM3 extracts were $75.23 \% \pm 4.55 \%, 17.01 \% \pm 1.33 \%$ and $4.33 \% \pm 3.15 \%$, respectively.

\section{Conclusion}


In this study, essential oils were extracted from China's unique spices, cassia bark, bay fruits and cloves, which are widely grown and used as condiments. This study extracted the essential oils from cassia bark, bay fruits, and cloves, which are widely cultivated and used as condiments. The results show that all of these have certain antibacterial activity on Vibrio parahaemolyticus, Listeria monocytogenes, and 4 types of Listeria. Among the three spices, cassia bark showed the greatest antimicrobial activity against $V$. parahaemolyticus and Listeria spp., while bay fruits had the lowest antimicrobial activity. Although the major component of both cassia bark and bay fruits essential oils was cinnamaldehyde, the antimicrobial activity of the extracts was significantly different between the two spices. The antimicrobial activity of cinnamaldehyde and eugenol have been previously demonstrated (Dhara and Tripathi, 2013; Anna et al., 2017; Liu et al., 2014).Therefore, extracts of cassia bark, bay fruits, and cloves could be an effective antimicrobials for controlling the growth of pathogenic microorganisms in foods.

Each spice has its own beneficial property to human health and the synergic effects of different spices can increase the potential properties (Yashin et al., 2017; Alan, 2019).Studies have reported the synergistic effects of using several essential oils in combination improves antimicrobial effects without raising their concentrations(Hussein et al., 2016; Bulent and W, 2017). While the antimicrobial activities of crude extracts of various spices have been studied, it is necessary to subdivide and purify the contents of the crude extracts, and determine the main active component as well as the underlining antimicrobial mechanism. Additional studies are needed to identify the active compounds mode of action and toxicity.

\section{Declarations}

\section{ACKNOWLEDGEMENTS}

This research was supported by the National Natural Science Foundation of China (31671779), Shanghai Agriculture Applied Technology Development Program (T20170404), Innovation Program of Shanghai Municipal Education Commission (2017-01-07-00-10-E00056).

\section{CONFLICT OF INTEREST}

There are no conflicts of interest to declare.

\section{References}

1. A CR, M WA, G SR, et al. (2019) Microbial study of household hygiene conditions and associated Listeria monocytogenes infection risks for Peruvian women. J Tropical medicine \& international health : TM \& IH 24

2. Alan JT. (2019) Health Benefits of Culinary Herbs and Spices. J Journal of AOAC International 102

3. Anna M, Ramona B, Erika C, et al. (2017) Antimicrobial activity of eugenol and essential oils containing eugenol: A mechanistic viewpoint. J Critical reviews in microbiology 43

4. Ashktorab H, Soleimani A, Singh G, et al. (2019) Saffron: The Golden Spice with Therapeutic Properties on Digestive Diseases. J Nutrients 11

5. Bajalan I, Rouzbahani R, Pirbalouti AG, et al. (2017) Antioxidant and antibacterial activities of the essential oils obtained from seven Iranian populations of Rosmarinus officinalis. J Industrial Crops \& Products 107

6. Bajpai VK, Sharma A and Baek K-H. (2013) Antibacterial mode of action of Cudrania tricuspidata fruit essential oil, affecting membrane permeability and surface characteristics of food-borne pathogens. J Food Control 32

Page $10 / 14$ 
7. Bulent $\mathrm{K}$ and W DAD. (2017) Mycotoxins in spices and herbs-An update. J Critical reviews in food science and nutrition 57

8. Calvo MM, Tzamourani A and Martinez-Alvarez O. (2021) Halophytes as a potential source of melanosisinhibiting compounds. Mechanism of inhibition of a characterized polyphenol extract of purslane (Portulaca oleracea). J Food Chemistry 355: 8

9. Chen P, Liu B, Liu X, et al. (2019) Ultrasound-assisted extraction and dispersive liquid-liquid microextraction coupled with gas chromatography-mass spectrometry for the sensitive determination of essential oil components in lavender. J Analytical Methods 11

10. Chin K-Y. (2016) The spice for joint inflammation: anti-inflammatory role of curcumin in treating osteoarthritis. J Drug Design, Development and Therapy 2016

11. da Silva BD, Bernardes PC, Pinheiro PF, et al. (2021) Chemical composition, extraction sources and action mechanisms of essential oils: Natural preservative and limitations of use in meat products. J Meat Science 176: 11

12. Dhara L and Tripathi A. (2013) Antimicrobial activity of eugenol and cinnamaldehyde against extended spectrum beta lactamase producing enterobacteriaceae by in vitro and molecular docking analysis. J European Journal of Integrative Medicine 5

13. Ding C, Ma J, Jiang W, et al. (2021) Chironomidae larvae: A neglected enricher of antibiotic resistance genes in the food chain of freshwater environments. J Environmental Pollution 285: 117486

14. El-Sayed SM and Youssef AM. (2019) Potential application of herbs and spices and their effects in functional dairy products. J Heliyon 5: e01989

15. Fidan H, Stefanova G, Kostova I, et al. (2019) Chemical Composition and Antimicrobial Activity of Laurus nobilis L. Essential Oils from Bulgaria. J Molecules 24

16. HelmyAbdou KA, Ahmed RR, Ibrahim MA, et al. (2019) The anti-inflammatory influence of Cinnamomum burmannii against multi-walled carbon nanotube-induced liver injury in rats. J Environmental Science and Pollution Research 26

17. Huang J, Chen B, Li H, et al. (2020) Enhanced antibacterial and antibiofilm functions of the curcumin-mediated photodynamic inactivation against Listeria monocytogenes. J Food Control 108

18. Hussein E-Z, Juan M-T, Ángel C-S, et al. (2016) Volatile Composition of Essential Oils from Different Aromatic Herbs Grown in Mediterranean Regions of Spain. J Foods (Basel, Switzerland) 5

19. Juan W, Hongliang H, C CR, et al. (2019) Drug-Conjugated Dendrimer Hydrogel Enables Sustained Drug Release via a Self-Cleaving Mechanism. J Molecular pharmaceutics 16

20. Kheawfu K, Pikulkaew S, Rades T, et al. (2018) Development and characterization of clove oil nanoemulsions and self-microemulsifying drug delivery systems. J Journal of Drug Delivery Science and Technology 46

21. Liu F, Goodarzi A, Wang H, et al. (2014) A combination of pharmacophore modeling, molecular docking and virtual screening for iNOS inhibitors from Chinese herbs. J Bio-Medical Materials and Engineering 24

22. Lv B, Jiang T, Wei H, et al. (2021) Transfer of antibiotic-resistant bacteria via ballast water with a special focus on multiple antibiotic-resistant bacteria: A survey from an inland port in the Yangtze River. J Marine Pollution Bulletin 166: 112166

23. Mahros MA, Abd-Elghany SM and Sallam KI. (2021) Multidrug-, methicillin-, and vancomycin-resistant Staphylococcus aureus isolated from ready-to-eat meat sandwiches: An ongoing food and public health concern. J International Journal of Food Microbiology 346: 109165

Page $11 / 14$ 
24. Masri S, Miller CS, Palmer RF, et al. (2021) Toxicant-induced loss of tolerance for chemicals, foods, and drugs: assessing patterns of exposure behind a global phenomenon. J Environmental Sciences Europe 33: 19

25. Mendes RdF, Pinto NdCC, Silva JM, et al. (2017) The essential oil from the fruits of the Brazilian spice Xylopia sericea A. St.-Hil. presents expressive in-vitro antibacterial and antioxidant activity. J Journal of Pharmacy and Pharmacology 69

26. Noman E, Al-Gheethi A, Radin Mohamed RMS, et al. (2021) Quantitative microbiological risk assessment of complex microbial community in Prawn farm wastewater and applicability of nanoparticles and probiotics for eliminating of antibiotic-resistant bacteria. J Journal of Hazardous Materials 419: 126418

27. Otunola GA and Afolayan AJ. (2018) In vitro antibacterial, antioxidant and toxicity profile of silver nanoparticles green-synthesized and characterized from aqueous extract of a spice blend formulation. J Biotechnology \& Biotechnological Equipment 32

28. Pandey AK, Chavez-Gonzalez ML, Silva AS, et al. (2021) Essential oils from the genus Thymus as antimicrobial food preservatives: Progress in their use as nanoemulsions-a new paradigm. J Trends in Food Science \& Technology 111: 426-441

29. Pasonen P, Ranta J, Tapanainen H, et al. (2019) Listeria monocytogenes risk assessment on cold smoked and salt-cured fishery products in Finland - A repeated exposure model. J International Journal of Food Microbiology 304

30. Qing L, Xiao M, Ya L, et al. (2017) Antibacterial and Antifungal Activities of Spices. J International journal of molecular sciences 18

31. Rui P, Tengfei X, Qingping W, et al. (2019) Comparative Genomic Analysis Reveals the Potential Risk of Vibrio parahaemolyticus Isolated From Ready-To-Eat Foods in China. J Frontiers in microbiology 10

32. Sepahpour S, Selamat J, Manap MYA, et al. (2018) Comparative Analysis of Chemical Composition, Antioxidant Activity and Quantitative Characterization of Some Phenolic Compounds in Selected Herbs and Spices in Different Solvent Extraction Systems. J Molecules 23

33. Serafini M and Peluso I. (2016) Functional Foods for Health: The Interrelated Antioxidant and Anti-Inflammatory Role of Fruits, Vegetables, Herbs, Spices and Cocoa in Humans. J Current Pharmaceutical Design 22

34. Tshabalala R, Kabelinde A, Kaptchouang Tchatchouang C-D, et al. (2021) Effect of Clove (Syzygium aromaticum) spice as microbial inhibitor of resistant bacteria and Organoleptic Quality of meat. J Saudi Journal of Biological Sciences 28: 3855-3863

35. Wu ST, Hammons SR, Wang J, et al. (2020) Predictive risk models combined with employee- and managementimplemented SSOPs identified and reduced Listeria monocytogenes prevalence in retail delis. J Food Control 109

36. Yang C, Zhang X, Fan H, et al. (2019) Genetic diversity, virulence factors and farm-to-table spread pattern of Vibrio parahaemolyticus food-associated isolates. J Food Microbiology 84

37. Yashin A, Yashin Y, Xia X, et al. (2017) Antioxidant Activity of Spices and Their Impact on Human Health: A Review. J Antioxidants 6

38. Zhang C, Fan L, Fan S, et al. (2019) Cinnamomum cassia Presl: A Review of Its Traditional Uses, Phytochemistry, Pharmacology and Toxicology. J Molecules 24

39. Zhang T-T, Lu C-L and Jiang J-G. (2016) Neuroprotective and Anti-Inflammatory Effects of Diphenylheptanes from the Fruits of Amomum tsaoko , a Chinese Spice. J Plant Foods for Human Nutrition 71

40. Zhiwei Z, Ruichao L, Lianwei Y, et al. (2019) Genetic Characterization of bla <sub>CTX-M-55</sub>-Bearing Plasmids Harbored by Food-Borne Cephalosporin-Resistant Vibrio parahaemolyticus Strains in China. J Frontiers

Page $12 / 14$ 
in microbiology 10

\section{Table}

Table 2 is available in the Supplemental Files section.

\section{Figures}
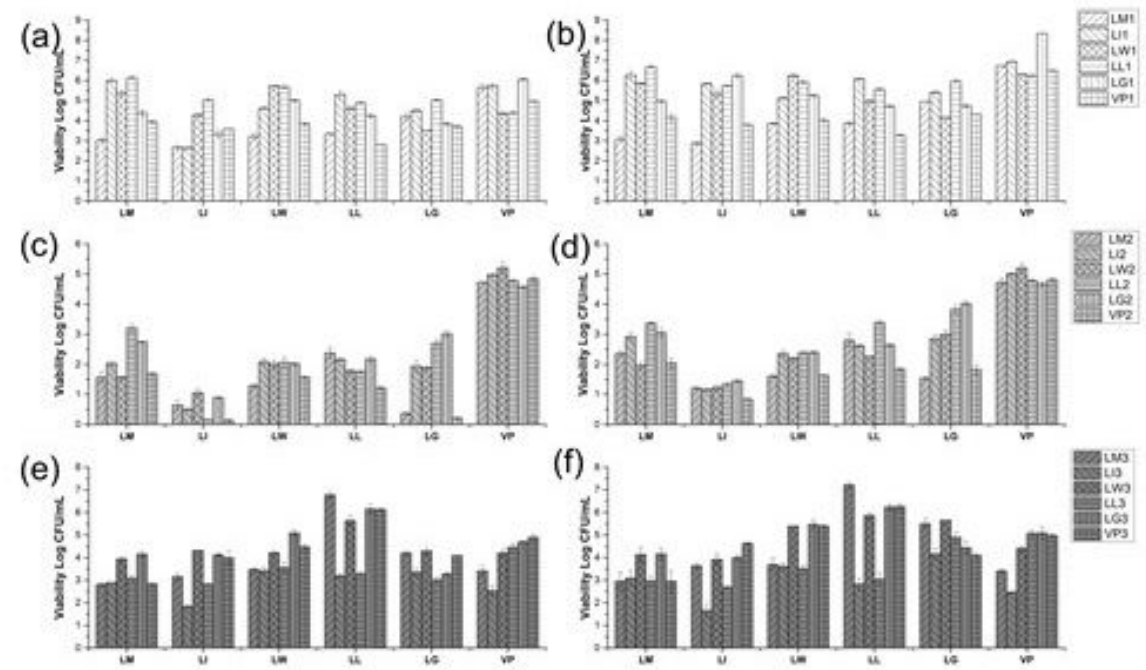

\section{Figure 1}

Effects of essentialoils on the viability of $V$. parahaemolyticus and Listeria spp. (a) strains cultured on nonselective medium with Cassiabark; (b) strains cultured on selective medium with Cassiabark; (c) strains cultured on nonselective medium with bay fruits; (d) strains cultured on selective medium with bay fruits; (e) strains cultured on nonselective medium with cloves; (f) strains cultured on selective medium with cloves. 

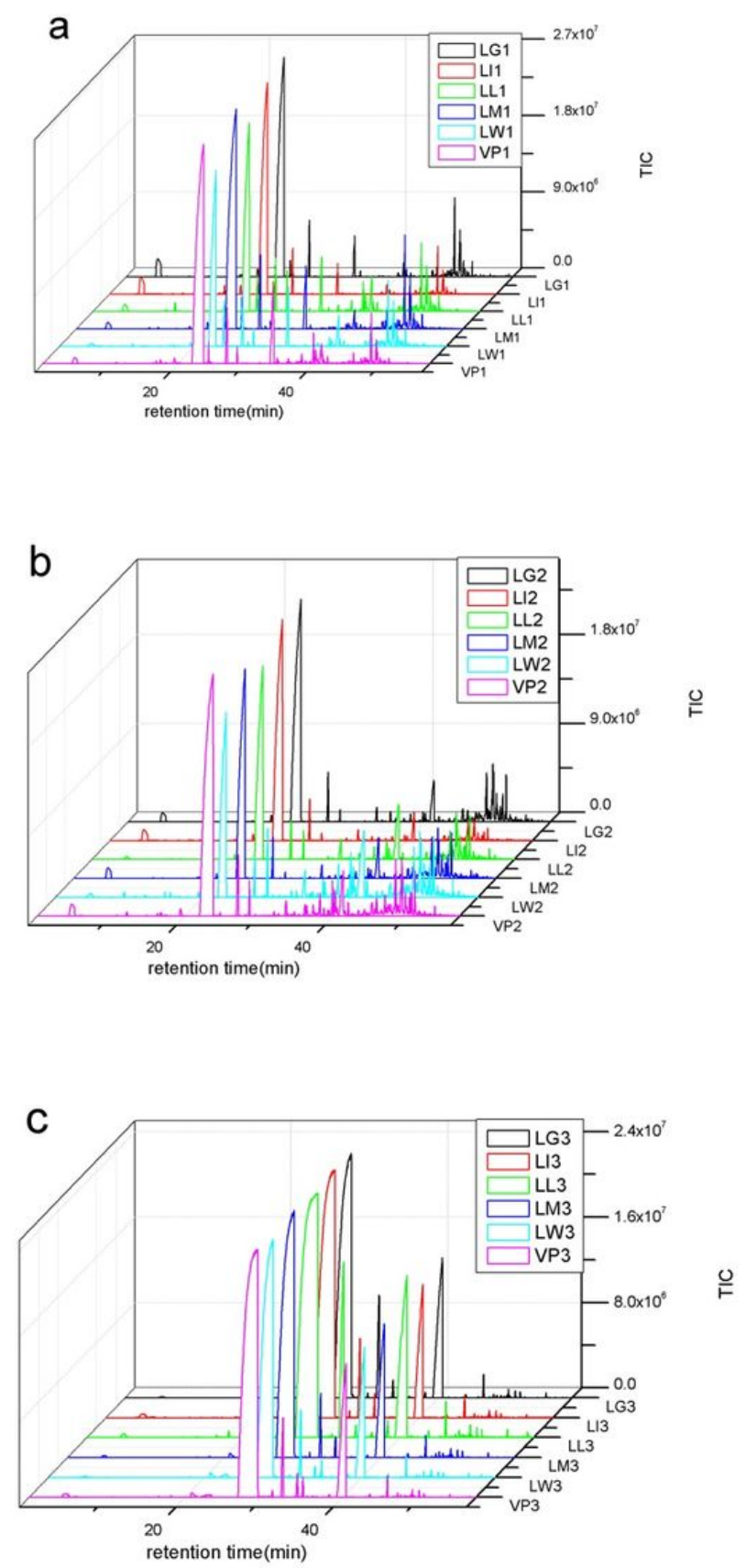

Figure 2

GC/MS spectrogram for the three spices extractedby the optimal extraction conditions against six tested strains. a, spectrogram of the cassia bark extracts; b,spectrogram of the bay fruits extracts;c,spectrogram of the cloves extracts.

\section{Supplementary Files}

This is a list of supplementary files associated with this preprint. Click to download.

- Table2.docx 